SANDIA REPORT

SAND97-8284 • UC-406

Unlimited Release

Printed August 1997
RECEIVED

SEP 261997

OSTI

\title{
Development of a Portable X-Ray and Gamma-Ray Detector Instrument and Imaging Camera for Use in Radioactive and Hazardous Material Management
}

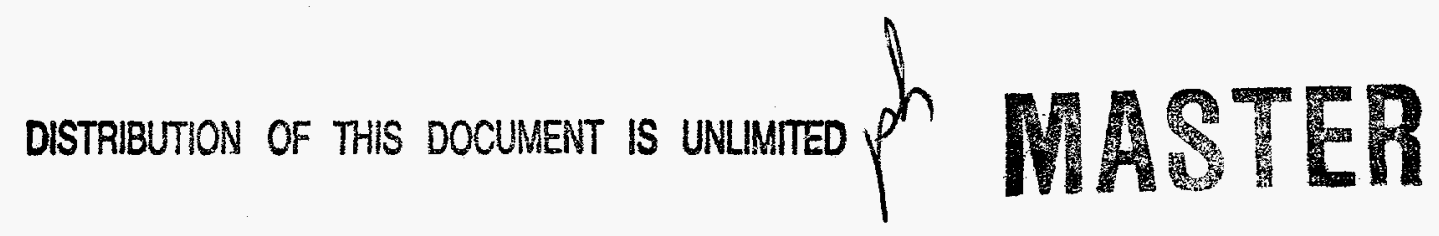

J. M. Van Scyoc, R. B. James, R. J. Anderson, A. J. Antolak, X. J. Bao, G. S. Bench, D. Boehme, B. A. Brunett, G. Buffleben, A. Burger, Y-C Chang, K-T Chen, E. Cross, M. DeVries, T. S. Gilbert, M. S. Goorsky, H. Hermon, N. R. Hilton, J S. Iwanczyk, L. A. Lim,J. C. Lund, J. M. Markakis, D. McArthur, D. S. McGregor, J, E. McKisson, D. L. Medlin, D. H. Morsé, M. Natarajan, R. W. Olsen, B. E. Patt, C. Perrino, A. E. Pontau, M. Roth, L. Salary, M. Schieber, T. E. Schlesinger, H-K Sim, R. H. Stulen, E. Soria, J. E. Toney, J. O. Weeks, H. W. Yao, H. Yoon

Prepared by

Sandia National Laboratories

Albuquerque, NewMexico 67185 and Livernore, California 94550

Sandia ts a multiprogram laboratory operated by Sandia Corporation, a Lockheed Martin Company, for the United States Department of Energy under Contract DE ACO4-94AL85000

Approved for public releâse; distribution is nimiled

17. Sandia National Laboratories Ger
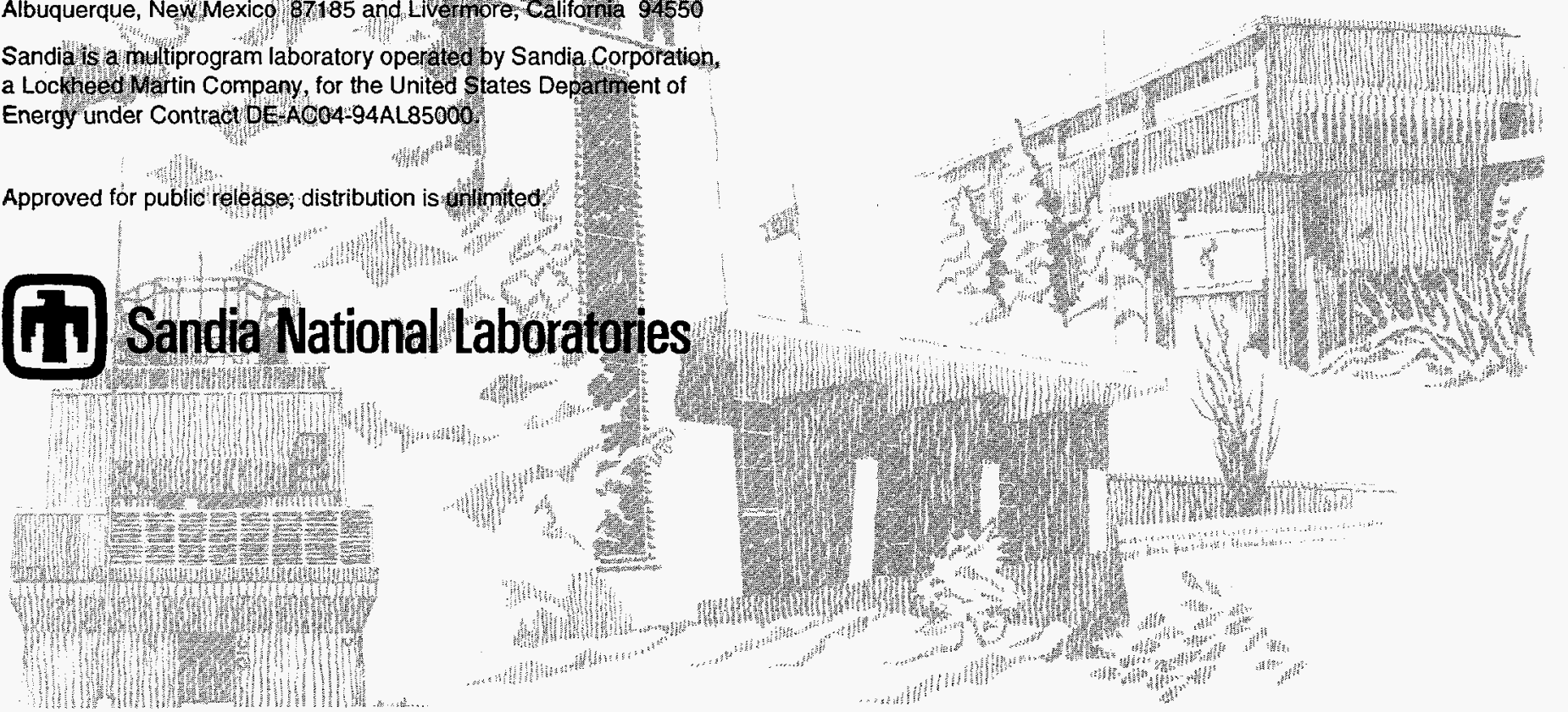
Issued by Sandia National Laboratories, operated for the United States Department of Energy by Sandia Corporation.

NOTICE: This report was prepared as an account of work sponsored by an agency of the United States Government. Neither the United States Government nor any agency thereof, nor any of their employees, nor any of their contractors, subcontractors, or their employees, makes any warranty, express or implied, or assumes any legal liability or responsibility for the accuracy, completeness, or usefulness of any information, apparatus, product, or process disclosed, or represents that its use would not infringe privately owned rights. Reference herein to any specific commercial product, process, or service by trade name, trademark, manufacturer, or otherwise, does not necessarily constitute or imply its endorsement, recommendation, or favoring by the United States Government, any agency thereof, or any of their contractors or subcontractors. The views and opinions expressed herein do not necessarily state or reflect those of the United States Government, any agency thereof, or any of their contractors.

Printed in the United States of America. This report has been reproduced directly from the best available copy.

Available to DOE and DOE contractors from

Office of Scientific and Technical Information

P.O. Box 62

Oak Ridge, TN 37831

Prices available from (615) 576-8401, FTS 626-8401

Available to the public from

National Technical Information Service

U.S. Department of Commerce

5285 Port Royal Rd

Springfield, VA 22161

NTIS price codes

Printed copy: A15

Microfiche copy: A01 


\section{DISCLAIMER}

Portions of this document may be illegible electronic image products. Images are produced from the best available original document. 


\title{
Development of a Portable X-ray and Gamma-ray Detector Instrument and Imaging Camera for Use in Radioactive and Hazardous Materials Management
}

J. M. Van Scyoc', R. B. James', R. J. Anderson ${ }^{1}$, A. J. Antolak ${ }^{1}$, X. J. Bao ${ }^{8}$, G. S. Bench $^{6}$, D. Boehme ${ }^{1}$, B. A. Brunett ${ }^{3}$, G. Buffleben ${ }^{1}$, A. Burger ${ }^{4}$, Y.-C. Chang ${ }^{11}$, K.T. Chen ${ }^{4}$, E. Cross ${ }^{1}$, M. DeVries ${ }^{12}$, T. S. Gilbert ${ }^{3}$, M. S. Goorsky ${ }^{10}$, H. Hermon ${ }^{1}$, N. R. Hilton ${ }^{9}$, J. S. Iwanczyk ${ }^{13}$, L. A. Lim ${ }^{12}$, J. C. Lund ${ }^{1}$, J. M. Markakis ${ }^{1}$, D. McArthur ${ }^{2}$, D. S. McGregor ${ }^{1}$, J. E. McKisson ${ }^{7}$, D. L. Medlin ${ }^{1}$, D. H. Morse ${ }^{1}$, M. Natarajan ${ }^{8}$, R. W. Olsen $^{3}$, B. E. Patt ${ }^{13}$, C. Perrino ${ }^{1}$, A. E. Pontau ${ }^{1}$, M. Roth ${ }^{5}$, L. Salary ${ }^{4}$, M. Schieber ${ }^{1}$, T. E. Schlesinger ${ }^{3}$, H.-K. Sim ${ }^{11}$, R. H. Stulen ${ }^{1}$, E. Soria ${ }^{1}$, J. E. Toney ${ }^{3}$, J. O. Weeks ${ }^{1}$, H. $\mathrm{Yao}^{12}, \mathrm{H}$. Yoon ${ }^{10}$

\author{
'Sandia National Laboratories, Livermore, CA 94550 \\ ${ }^{2}$ Sandia National Laboratories, Albuquerque, NM 87185 \\ ${ }^{3}$ Carnegie Mellon University, Pittsburgh, PA 15213 \\ ${ }^{4}$ Fisk University, Nashville, TN 37208 \\ ${ }^{5}$ Hebrew University, Jerusalem, Israel 9190 \\ ${ }^{6}$ Lawerence Livermore National Laboratory, Livermore, CA 94550 \\ ${ }^{7}$ Radiation Technologies, Inc., Alachua, FL 32615 \\ ${ }^{8}$ TN Technologies, Round Rock, TX 78680 \\ ${ }^{9}$ University of Arizona, Tucson, AZ 85724 \\ ${ }^{10}$ University of California, Los Angeles, CA 90095 \\ ${ }^{11}$ University of Illinois, Urbana, IL 61801 \\ ${ }^{12}$ University of Nebraska, Lincoln, NB 68588 \\ ${ }^{13}$ Xsirius, Inc., Camarillo, CA 93012
}

\begin{abstract}
The overall goal of this LDRD project was to develop instruments for use in the management of radioactive and hazardous wastes. Devices for identifying and imaging such wastes are critical to developing environmental remediation strategies. Field portable units are required to enable the on-site analysis of solids, liquids, and gas effluents. Red mercuric iodide $\left(\alpha-\mathrm{HgI}_{2}\right)$ is a semiconductor material that can be operated as a high-energy-resolution radiation detector at ambient temperatures. This property provides the needed performance of conventional germanium- and silicon-based devices, while eliminating the need for the cryogenic cooling of such instruments. The first year of this project focused on improving the materials properties of the mercuric iodide to enable the new sensor technology; in particular the charge carrier traps limiting device performance were determined and eliminated. The second year involved the development of a field portable $x$-ray fluorescence analyzer for compositional analyses. The third and final year of the project focused on the development of imaging sensors to provide the capability for mapping the composition of waste masses. This project resulted in instruments useful not only for managing hazardous and radioactive wastes, but also in a variety of industrial and national security applications.
\end{abstract}




\section{Acknowledgment}

We gratefully acknowledge support of this project (case 3515.170) by Laboratory Directed Research and Development (LDRD) funds. In addition, we'd like to acknowledge the efforts of the various researchers who have contributed to this project and have helped make it a success. 
Contents

Preface..

Summary

Nomenclature

Introduction.

Background..

Improvement of Mercuric Iodide Materials.

Development of Mercuric Iodide Portable X-ray Fluorescence Analyzer.

Development

Conclusions

References.

APPENDIX A

(Reprints - Removed
for separate
Processing

5 


\section{Preface}

The ability to detect, identify, and image various forms of hazardous, radioactive, and mixed wastes is critical for the development and implementation of environmental remediation programs. Detailed information about elemental and radionuclide content, concentration, and distribution are required to effectively localize and process these wastes. One of the most common methods for elemental analyses is $x$-ray fluorescence spectroscopy (XRF), which can be used to identify and quantify elements from a large portion of the periodic table to the part-per-thousand level. For the identification of radionuclides, energy spectroscopy is used. While both of these techniques are readily available in any standard analytical laboratory, they have been traditionally either unavailable or impractical for field use. In order to obtain the high energy resolution required for these applications, semiconductor detectors are required. For XRF, the conventional $x$-ray spectrometer used is lithium-drifted silicon ( $\mathrm{Si}: \mathrm{Li}$ ), while for the energy spectroscopy of radionuclides high-purity germanium (HPGe) is the choice. Both of these semiconductor detectors require cryogenic cooling (liquid nitrogen at $77 \mathrm{~K}$ ) to operate, as the thermal leakage currents in these devices at ambient temperatures overwhelm the signal currents. In addition to the requirement of cooling during operation for both Si:Li and HPGe, Si:Li detectors also generally require continuous cooling during storage to avoid device degradation. These cryogenic cooling requirements introduce weight, size, maintenance, and preparation-time issues to the associated instruments, which tend to limit their use in the field.

In recent years there has been a push to develop alternative semiconductor materials that eliminate these problems. Of these room-temperature semiconductor detector materials, red alpha-phase mercuric iodide $\left(\alpha-\mathrm{HgI}_{2}\right)$ has shown the greatest promise, particularly for the demands of XRF on resolving low-energy $\mathrm{x}$-rays. In addition, mercuric iodide has the capability to efficiently detect and identify higher energy gamma photons from radionuclides. An instrument built around a mercuric iodide sensor element could be used for XRF and gamma spectroscopy in the field in the desired "anytime, any-where" mode of operation.

However, the main obstacle to the implementation of such systems has been the availability of high quality mercuric iodide devices. The trapping of electrical charge carriers in the bulk crystal reduces the energy resolution and low energy spectroscopy capabilities of the detector. In addition, the effects of mobile impurity-related defects in the device leads to polarization phenomena, which are the changes in device response versus time. Therefore, there have been significant efforts expended on identifying and eliminating the impurities and other charge-trapping defects.

Once the material had reached a sufficient development level, it was possible to fabricate prototype detectors and instruments. The first instrument developed was a portable XRF unit for the field analysis of toxics in various sample forms. The XRF instrument was designed to be carried and operated by a single technician for a day. The only maintenance requirements are the recharging of the batteries at the end of the workday. Once this instrument was implemented the focus shifted to imaging devices that could be used to determine the distribution of radionuclides in the environment. Because of the semiconductor operation of mercuric iodide detectors, it is possible to use lithographic fabrication procedures to yield a detector device with $\mathrm{high}$ spatial resolution as well as good energy spectrum resolution.

The work to improve mercuric iodide materials and develop prototype portable XRF analyzers and imaging instruments is discussed in this report. 


\section{Summary}

The end goal of this project was to provide a capability in the characterization of hazardous and radioactive wastes that is currently unavailable. New instruments based on mercuric iodide nuclear radiation spectrometers that can operate at ambient temperatures were developed in order to provide detailed analytical capabilities in the field. The primary enabling technology for such instruments is the mercuric iodide sensor itself. Therefore, the first year of this project focused on improving the yield and performance of mercuric iodide detectors by reducing the number of charge trapping defects. The second year focused on developing and building a prototype portable $x$-ray fluorescence spectroscopy analyzer for use in the elemental characterization of toxics in the environment. The third and final year of the project focused on developing and building a prototype gamma-ray imaging camera to be used in determining the spatial distribution of radioactive wastes in a given region. The imaging system consists of a $\mathrm{n}$ orthogonal strip detector made from $\mathrm{HgI}_{2}$ crystals. The detectors utilize an $8 \times 8$ orthogonal strip configuration with 64 effective pixels. The detector arrays are $1 \mathrm{~cm}^{2}$ devices with a strip pitch of approximately $1.2 \mathrm{~mm}$ (producing pixels of $1.2 \mathrm{~mm} \times 1.2 \mathrm{~mm}$ ). The readout electronics consist of parallel channels of preamplifier, shaping amplifier, discriminators, and peak sensing ADC. The preamplifiers are configured in hybrid technology, and the rest of the electronics are implemented in NIM and CAMAC with control via a Power Macintosh computer. The software used to readout the instrument is capable of performing intensity measurements as well as spectroscopy on all 64 pixels of the device. We report on the performance of the system imaging gamma-rays in the 20-500 keV energy range and using a pin-hole collimator to form the image. Taken together, these instruments provide new tools that can be provided to workers responsible for characterizing and remediating hazardous and radioactive wastes. 


\section{Nomenclature}

$\begin{array}{ll}\text { ADC } & \text { analog to digital converter } \\ \text { AES } & \text { Auger electron spectroscopy } \\ \text { AFM } & \text { atomic force microscopy } \\ \text { ASIC } & \text { application specific integrated circuit } \\ \alpha-H g I_{2} & \text { alpha-phase mercuric iodide } \\ \text { CAMAC } & \text { Computer Automated Measurement and Control } \\ \text { CMOS } & \text { complementary metal-oxide-semiconductor } \\ \text { DIP } & \text { dual in-line package } \\ \text { DSC } & \text { differential scanning calorimetry } \\ \text { EDP } & \text { electrodrift purification } \\ \text { GUI } & \text { graphical user interface } \\ \text { HPGe } & \text { high purity germanium } \\ \text { ICP-AES } & \text { inductively-coupled atomic emission spectroscopy } \\ \text { ICP-MS } & \text { inductively-coupled mass spectroscopy } \\ \text { MCA } & \text { multichannel analyzer } \\ \text { NEST } & \text { Nuclear Emergency Search Team } \\ \text { NIM } & \text { Nuclear Instrumentation Module } \\ \text { PICTS } & \text { photo-induced current transient spectroscopy } \\ \text { PIXE } & \text { proton-induced x-ray emission } \\ \text { PL } & \text { photoluminescence } \\ \text { PMT } & \text { photomultiplier tube } \\ \text { PR } & \text { photoresponse mapping } \\ \text { RSM } & \text { reciprocal space map } \\ \text { Si:Li } & \text { lithium-drifted silicon } \\ \text { SNM } & \text { special nuclear material } \\ \text { TAXRD } & \text { triple axis x-ray diffraction } \\ \text { TCT } & \text { transient charge technique } \\ \text { TEM } & \text { transmission electron microscopy } \\ \text { TSC } & \text { thermally stimulated currents } \\ \text { VASE } & \text { variable angle spectroscopic ellipsometry } \\ \text { XRF } & \text { x-ray fluorescence spectroscopy } \\ \text { XRDT } & \text { x-ray diffraction topography } \\ \text { Z } & \text { atomic number }\end{array}$




\section{Development of a Portable X-ray and Gamma-ray Detector Instrument and Imaging Camera for Use in Radioactive and Hazardous Materials Management}

\section{Introduction}

There are many applications in hazardous and radioactive materials management where the ability to characterize in real-time the elemental and radiological composition of a waste mass can greatly enhance the effectiveness and efficiency of an operation. Instruments conventionally available for detailed elemental and radiological identification and quantification are generally too bulky and maintenance-intensive for practical use in the field. The conventional field portable devices have too poor of performance for the detailed analyses required. Therefore, the goal of this project was to develop new tools based on the room-temperature nuclear radiation spectrometer mercuric iodide. The two tools most of use are a portable $x$-ray fluorescence (XRF) analyzer and a radionuclide imaging camera, both of which have been developed.

\section{Background}

There are many types of devices available for detecting $\mathrm{x}$-rays and gammarays over a wide energy range. Gas-filled detectors generally have too low a sensitivity density for anything other than very low energy $x$-rays and can be damaged by rough handling; therefore, solid-state devices are most appropriate for portable applications. While scintillators can have a high detection efficiency, their energy resolution is too poor for the spectroscopy capabilities required. Energy resolution is most obviously important for separating closely spaced emissions. As Figure 1 shows, however, it is also important for detecting weak signals in a noisy background, as may be found in the complicated environment of hazardous and radioactive wastes measurements. Semiconductor detectors are then the device of choice for applications requiring energy spectroscopy. The conventional semiconductors of choice have become lithium-drifted silicon (Si:Li) for $\mathrm{x}$ rays and high-purity germanium (HPGe) for gamma-rays. While these two materials provide for devices with ultra-high energy resolution, they require continual cryogenic (liquid nitrogen at $77 \mathrm{~K}$ ) cooling during operation. This limits their applicability for field portable units. ${ }^{1}$

Given this, there has been considerable interest in developing semiconductor detectors that operate at room temperature. Several materials have been considered, but only a select few have shown sufficient promise to warrant advancement to the point where they can be applied. Mercuric iodide $\left(\mathrm{HgI}_{2}\right)$ has many optimal properties which have lead to it being the leading candidate material for many applications. ${ }^{2-4} \mathrm{HgI}_{2}$ has a large bandgap of $2.13 \mathrm{eV}$ at room-temperature which leads to a high electrical resistivity on the order of $10^{13} \Omega^{*} \mathrm{~cm} .^{5}$ This high resistivity leads to very low dark currents in the detector, which reduces the amount of noise degradation in the output spectrum. This is particularly critical for XRF where high energy resolution is required for low energy $x$-ray photons down to a few keV. Mercuric iodide also has a high average atomic number $(Z)$, which yields a high efficiency $f$ or stopping higher energy gamma-photons. This is useful for the spectroscopy and imaging of radioactive materials which can emit photons with energies up 
to several hundred $\mathrm{keV}$. Therefore, mercuric iodide has been known as a $\mathrm{n}$ excellent possibility for use in spectrometers designed to operate anywhere in the $\mathrm{x}$-ray and gamma-ray range for many years. ${ }^{6}$

However, mercuric iodide has several problems that limit the immediate implementation of the desired characterization tools. The material itself is mechanically soft and has aging problems associated with the sublimation of material from surfaces exposed to air. In addition, the material is significantly degraded if heated much above room-temperature, and cannot be grown from the melt. These problems are merely issues that complicate the growth and processing of the device, but that have been addressed. The more pressing issue, however, is the electrical performance of the semiconductor. Figure 2 shows the basic operation of a mercuric iodide detector. An incoming photon creates a photoelectron which rapidly passes its energy into the creation of electron-hole pairs. These mobile charge carriers are then swept in opposite directions by the applied electric field. The motion of these carriers gives rise to a current signal in the device leads and external circuit, which is then the signal measured and quantified. Therefore, the critical step in the operation of the device is the successful transport of the carriers from their creation point through the bulk of the mercuric iodide to their respect electrodes. I $n$ mercuric iodide, there are charge carrier traps that remove the carriers from their transport, thus degrading the signal measured. These traps can $b$ e caused by crystallinity defects, impurities, etc. The key to providing mercuric iodide-based instruments, then, is the improvement of the material to reduce these charge-causing defects to an acceptable level.

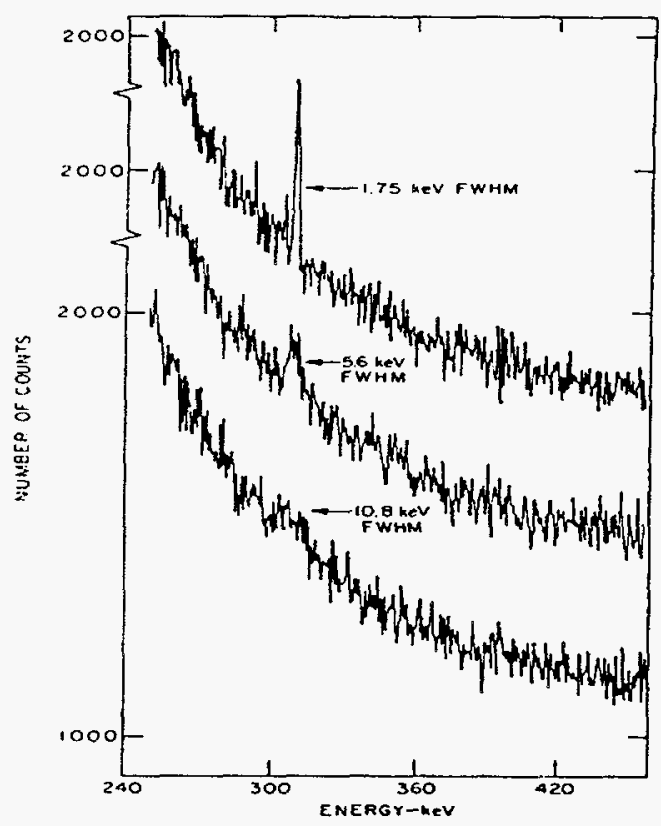

Figure 1. Simulated gamma-ray spectra showing the effect of detector energy resolution on the detectability of minority constituents in a strong background. (From Reference 1) 


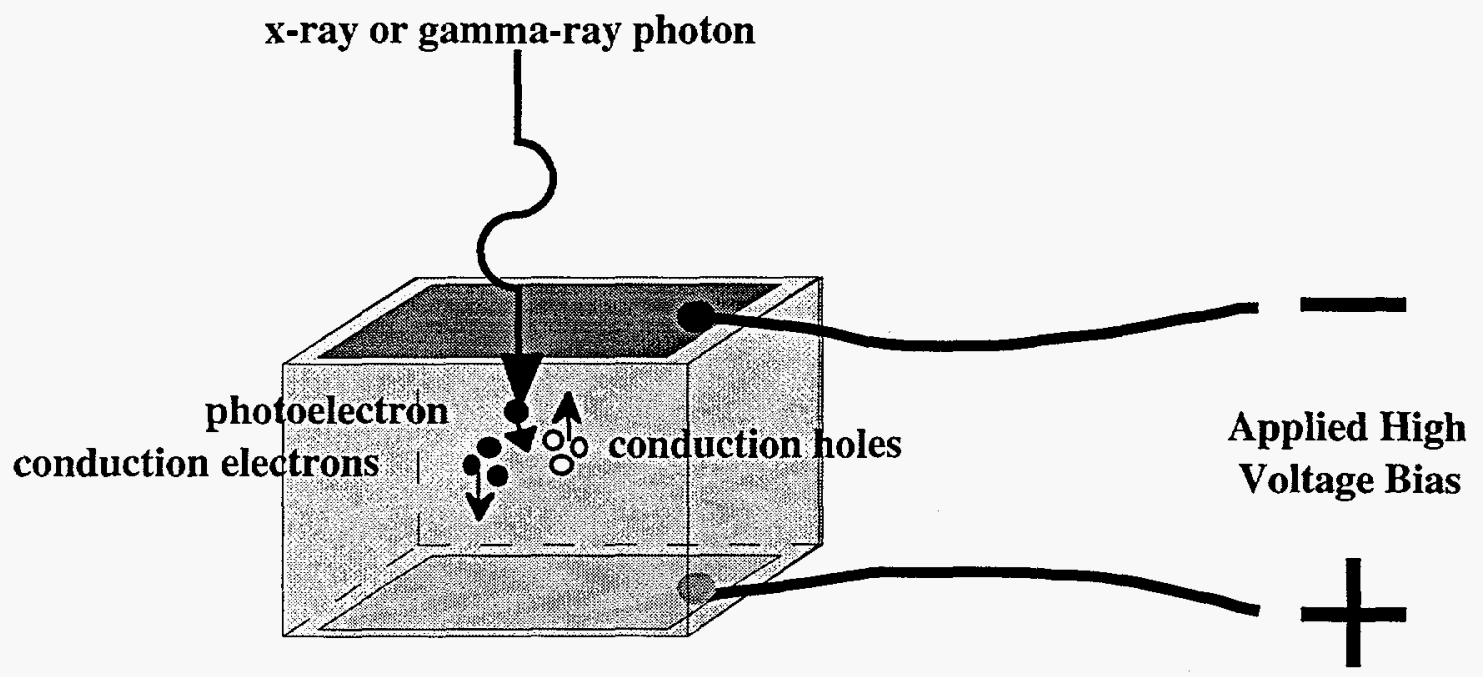

Figure 2. Schematic of mercuric iodide nuclear radiation detector operation. 


\section{Improvement of Mercuric lodide Materials}

As discussed above, charge trapping has been the primary problem limiting the application of mercuric iodide to radiation detector purposes. The effects of trapping can be seen clearly in the spectral performance of the devices for the radioisotope americium-241 $\left({ }^{241} \mathrm{Am}\right)$, as shown in Figure 3. ${ }^{241} \mathrm{Am}$ emits gamma photons of one midrange photon energy, $59.54 \mathrm{keV}$, and several lower energy $x$-ray peaks from the de-excitation of daughter products. The spectral peaks, which optimally would be very sharp and symmetric Gaussian-shaped, are broadened and asymmetric. This is most clearly seen at the $60 \mathrm{keV}$ line, where a low-channel-side "hole-tailing" occurs. The holetailing results from some of the detected events having decreased pulse height due to the trapping of the transporting holes.

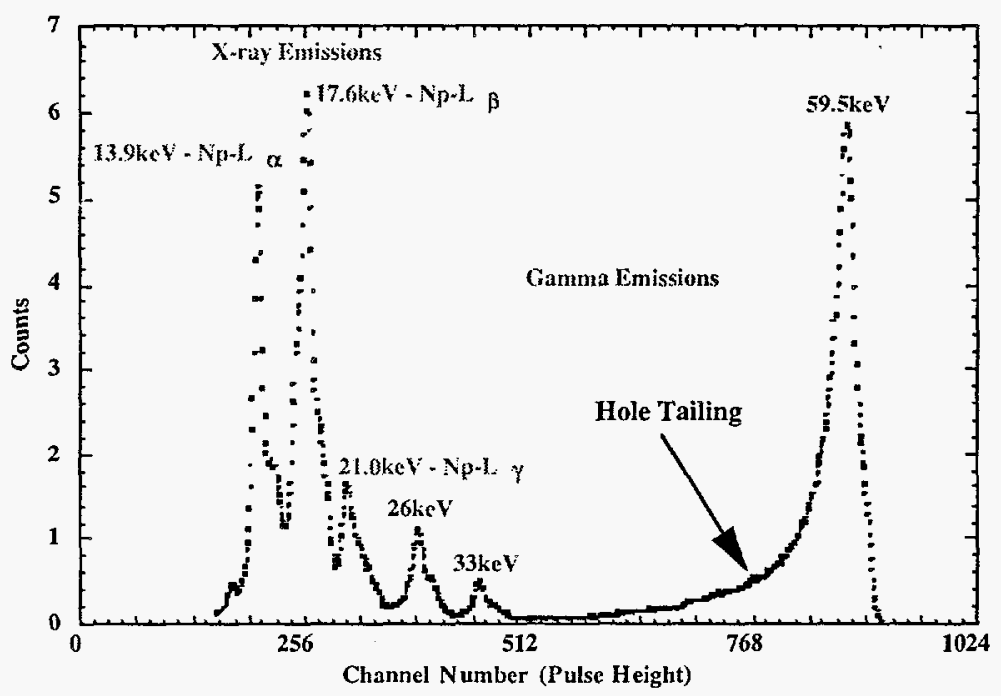

Figure 3. Spectrum of ${ }^{241} \mathrm{Am}$ from a $1 \times 1 \times 0.1 \mathrm{~cm}^{3} \mathrm{HgI}_{2}$ detector exhibiting hole tailing.

It is possible, however, to produce mercuric iodide detectors which exhibit excellent spectral properties. Figure 4 shows the spectrum from the same radioisotope, but with a detector actually used in one of the instruments developed for this project. Here the peaks are much sharper and more symmetric. The hole-tailing is still visible, but it is now at a level that does not prevent the usage of the detector for high resolution spectroscopy. A new "peak" does show up, but this is related to Compton scattering processes, and is intrinsic to the geometry of the measurement.

The key for providing the desired instrumentation is the improvement of the charge transport properties in the mercuric iodide. This is achieved by improving the materials properties of bulk mercuric iodide. The approach for doing this is to couple basic materials measurements with detector evaluations to determine the materials properties most negatively affecting device performance. A wide variety of materials measurements were applied to this problem. These tools included high-resolution triple-axis $x$-ray diffraction (TAXRD) and $x$-ray diffraction topography (XRDT), transmission electron microscopy (TEM), atomic force microscopy (AFM), proton-induced $x$-ray emission (PIXE), quantitative chemical analyses such as inductively-coupled atomic emission spectroscopy or mass spectroscopy (ICP-AES and ICP-MS), photoluminescence spectroscopy (PL), differential scanning calorimetry (DSC), transient charge technique (TCT), thermally stimulated currents (TSC), photo-induced current transients spectroscopy (PICTS), Auger electron 
spectroscopy (AES), and variable angle spectroscopic ellipsometry (VASE). The primary device evaluation tools included current-voltage curves (I-V), photoresponse mapping (PR), and nuclear spectroscopic response. The following paragraphs highlight a few examples of these measurements.

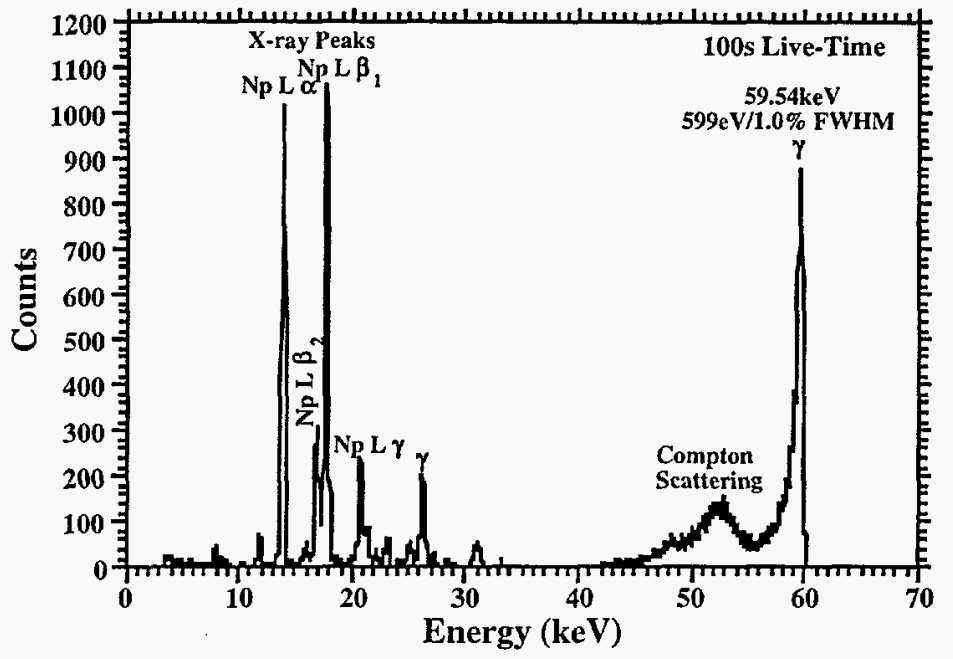

Figure 4. Spectrum of ${ }^{241} \mathrm{Am}$ from a $5 \times 5 \times 0.5 \mathrm{~mm}^{3} \mathrm{HgI}_{2}$ detector, demonstrating the excellent energy resolution possible in these devices $(600 \mathrm{eV}$ at $60 \mathrm{keV}$, or $1.0 \%)$.

One origin for charge-trapping defects is in the imperfection of the crystal structure of the bulk mercuric iodide. Any perturbations in the regularity of the atomic structure and its associated potential field can lead to the formation of trapping centers. These defects can range from simple point defects such as vacancies or interstitials through line defects such as dislocations to planar and three-dimensional defects such as grain boundaries. Changes in local lattice parameter lead to strains which also can introduce traps. Triple axis $\mathrm{x}$ ray diffraction (TAXRD) is a method that can give very detailed information on the localized crystalline perfection. It can separately quantify the amount of lattice strain, which is changes in atomic spacing, and lattice mosaicity, which can be viewed as the variation in tilts for small sub-crystals. Figure 5 shows TAXRD-measured reciprocal space maps (RSM) for good and poor performing mercuric iodide detectors.

Another potential origin of charge traps is from impurities in the mercuric iodide. A wide range of elements and molecules can end $u p$ incorporated into the mercuric iodide during growth or subsequent processing. Certain metallic elements, such as copper $(\mathrm{Cu})$ and silver (Ag) are particularly problematic, as they introduce device-killing traps and have a high diffusivity in mercuric iodide, even at room temperature. Any $\mathrm{Cu}$ or $\mathrm{Ag}$ that comes in contact with the mercuric iodide will readily diffuse into the bulk. One place that these impurities can be introduced is during the chemical processing required to fabricate detectors. A simple, yet powerful characterization tool that has been widely applied to mercuric iodide is lowtemperature photoluminescence (PL). In PL the cryogenically cooled (liquid helium at $4.2 \mathrm{~K}$ ) sample is excited by a laser beam to produce a large number of free carriers; as these carriers recombine they re-emit photons of different energies or wavelengths whose spectrum is captured. The wavelength of these emissions gives the energy level of the associated radiative trap, and the intensity is related to the trap level density. Figure 6 shows the PL spectrum from mercuric iodide before and after exposure to a Ag-doped etchant solution. The appearance of a new peak, whose wavelength is that of the trap level 
associated with silver impurities, indicates that the silver from the etchant $\mathrm{h}$ as been incorporated into the bulk mercuric iodide.

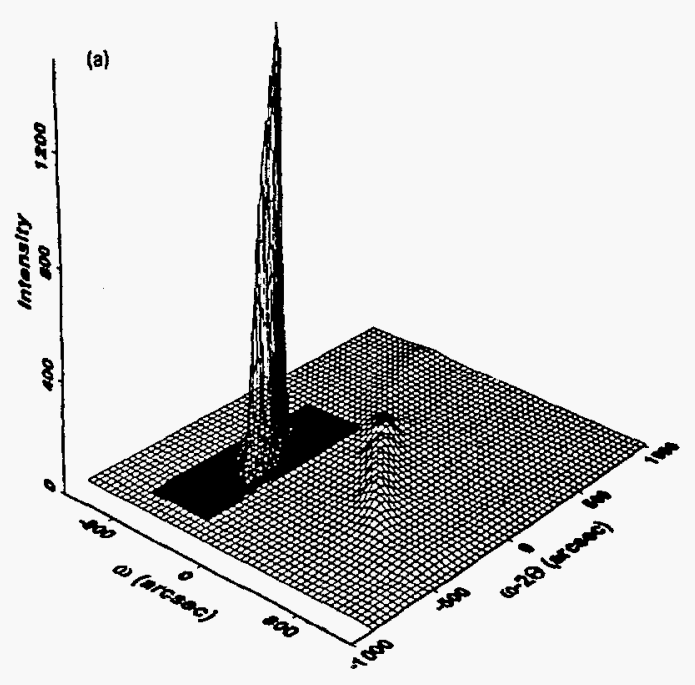

Figure 5. Triple axis $\mathrm{x}$-ray diffraction (TAXRD) analysis of $\mathrm{HgI}_{2}$ revealing differences between "good" (spectrometer) and "bad" (counter) detectors. The reciprocal space maps (RSM) separate the diffraction broadening due to mosaicity ( $\omega$ axis) and strain ( $\omega-2 \theta$ axis), with the good detector having a much sharper, more intense peak. The RSM on the left (a) shows both the good and bad devices, while the RSM on the right (b) is a blowup of just the bad device. The angular FWHM (on the $\omega$ axis) for the good detector is 4 arcseconds, while it is 170 arcseconds for the bad one.

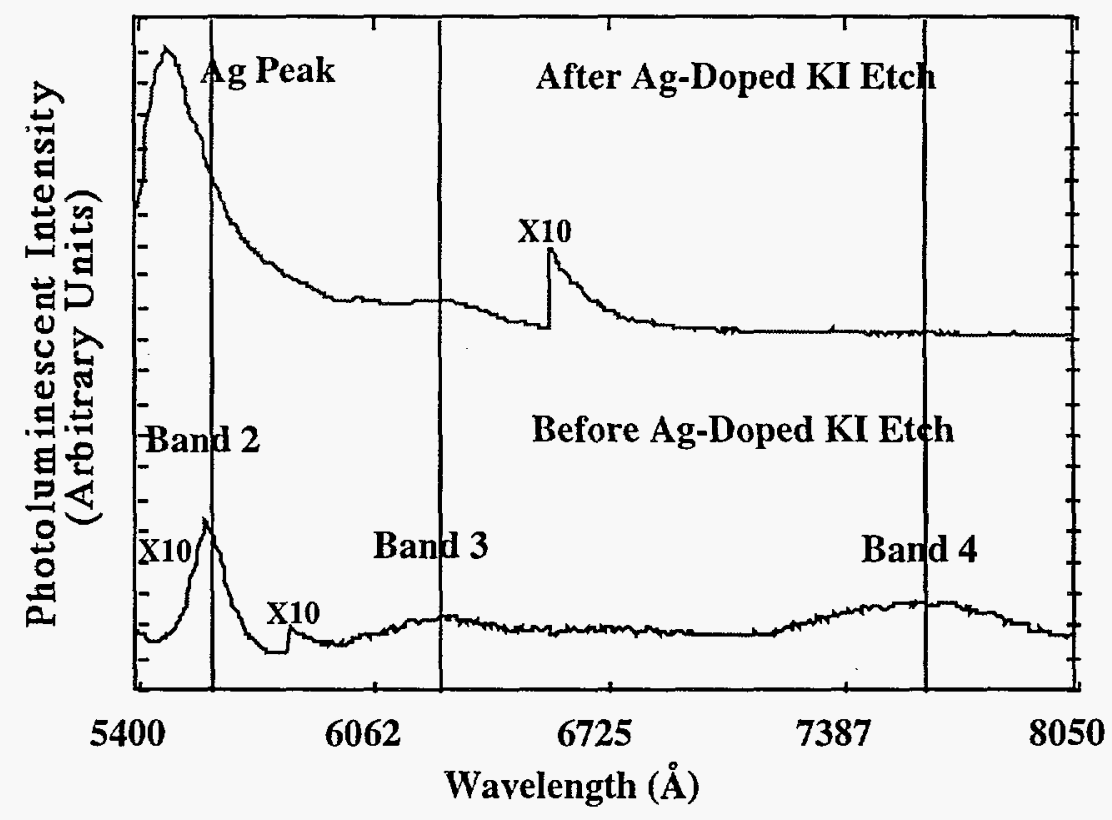

Figure 6. Photoluminescence analysis of $\mathrm{HgI}_{2}$ revealing introduction of $\mathrm{Ag}$ from the etchant.

The problem of impurities introduced during processing can be reduced by using very high purity processing materials. However, there are also impurities introduced into the original mercuric iodide starting materials that 
are incorporated during crystal growth. It is most critical to remove these impurities prior to the growth of the actual detector crystal, not only for the elimination of the impurity itself from the detector, but also to remove the impurity's impact on the growth process. A new method for removing certain electrically active and highly detrimental impurities has been developed and patented. ${ }^{7}$ This method relies on the electrically charged and mobile nature of these impurities in the bulk mercuric iodide; these impurities are "swept" from the mercuric iodide center section into sacrificial end regions. A useful method for quantifying the impurities in mercuric iodide has been inductively-coupled mass spectroscopy (ICP-MS). Figure 7 shows the results of an electrodrift purified mass of mercuric iodide, as measured by ICP-MS, demonstrating purification by a factor of 100 .

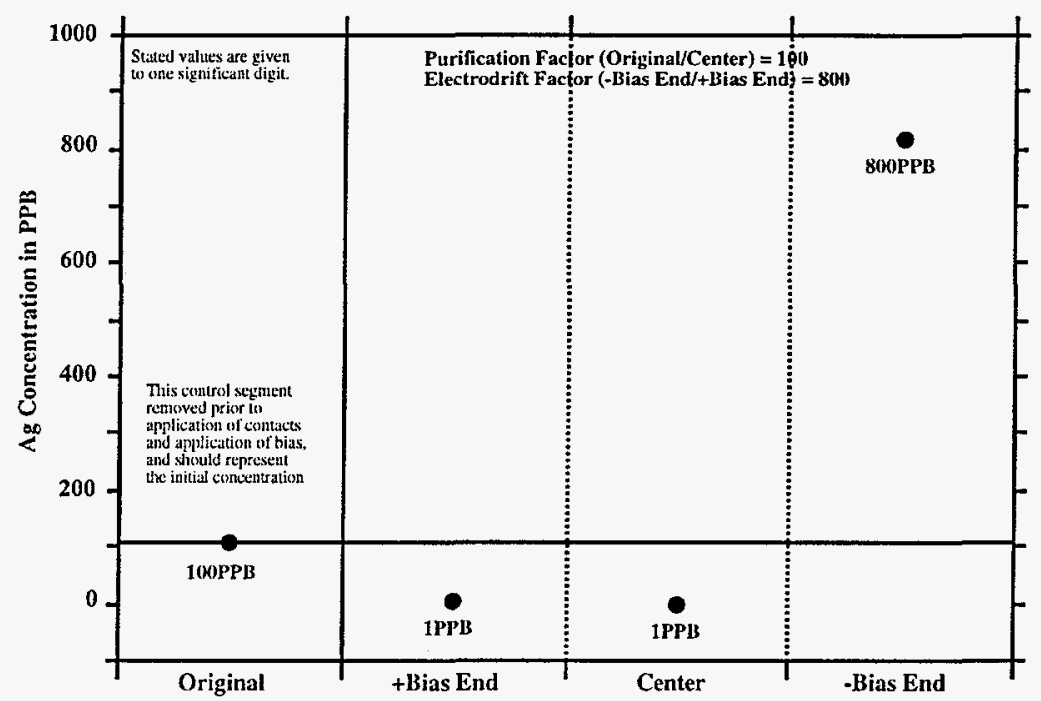

Figure 7. Chemical analysis (ICP-MS) results quantifying the electrodrift purification removal of $\mathrm{Ag}$ from a bulk polycrystalline sample of $\mathrm{HgI}_{2}$.

These and other types of measurements done on mercuric iodide are discussed further in Reference 8. 


\section{Development of a Mercuric lodide Portable X-ray Fluorescence Analyzer}

$\mathrm{X}$-ray fluorescence spectroscopy (XRF) is a very commonly used technique for elemental analyses of various forms of materials in the laboratory. XRF involves the excitation of the inner shell electrons of the atoms in the sample by means of an incident $x$-ray beam, generally from an electrical x-ray tube. As these electrons return to their ground (unexcited) state, they emit their excess energy in the form of electromagnetic photons in the $x$-ray $r$ ange. Because the electrons can only exist in finite, quantized energy states, the energy of these emitted $x$-rays is a constant for the de-excitation of a given electron state. Because the energies of these states are different for each element, the energies of the emitted $x$-rays are characteristic for each element. Each element will emit a set of $x$-rays at a well-defined set of energies. In general, the lower two series of these sets of emissions -- the $\mathrm{K}$ and $L$ shell level emissions -- will be readily excitable and detectable. Within each of these series are several energies. The analysis of XRF, then, is essentially the pattern matching of an unknown, complicated spectrum with the underlying elemental spectra. In order to do this, the $x$-ray detector must be sensitive to a wide range of $x$-ray energies ( $1 \mathrm{keV}$ to $100 \mathrm{keV})$, and have very high energy resolution (a few $100 \mathrm{~s}$ of $\mathrm{eV}$ ) in order to separate closely spaced peaks.

For a field portable unit, an electrical $x$-ray tube excitation source is impractical, so radioisotopes are used. With the use of three different radioisotopes, a large fraction of the periodic table is accessible, from sodium $(\mathrm{Na}, \mathrm{Z}=11)$ to Uranium $(\mathrm{U}, \mathrm{Z}=92)$. Iron-55 $\left({ }^{55} \mathrm{Fe}\right)$, with emissions around $6 \mathrm{keV}$ is useful for the low atomic number elements, cadmium-109 $\left({ }^{109} \mathrm{Cd}\right)$ is useful for the mid-range (transition metal) elements, and americium-241 ( $\left.{ }^{241} \mathrm{Am}\right)$ covers the high atomic elements. A measurement sequence involves taking a separate spectrum with each of these three sources for a completely unknown sample, or fewer of the sources if only a few elements in the sample are of interest.

The detector is a mercuric iodide spectrometer, that is cooled slightly (along with the preamplifier input stage) with a low power thermoelectric cooler to further improve energy resolution. The detector is kept under a continuous bias of about $1000 \mathrm{~V}$ ( 1000 to $2000 \mathrm{~V}$ per mm of detector thickness) at all times to avoid polarization problems. Because of the very small dark currents in mercuric iodide detectors, the battery used for this biasing lasts about six months. The thermoelectric cooler and signal chain electronics -preamplifier, shaping electronics, analog to digital converter (ADC), and multichannel analyzer (MCA), along with the digital processing electronics and computer are powered by rechargeable nickel-cadmium batteries designed for an eight-hour use before recharge. The entire unit can be readily carried by a field worker, with the computer, ADC, and MCA in a shoulder-strapped box, and the detector, preamplifier, and sources in a handheld probe head. Figure 8 shows a schematic of the instrument configuration.

Once the portable XRF instrument had been assembled, several samples were studied to characterize its capabilities. Figure 9 shows the spectrum obtained with the ${ }^{55} \mathrm{Fe}$ source on a sample of potassium chloride $(\mathrm{KCl})$ salt. As can be seen, the $\mathrm{K}$ and $\mathrm{Cl} \mathrm{K}_{\alpha}$ peaks are readily separable. The low channel noise peak is just starting to rise at $1 \mathrm{keV}$, indicating that the detector could be used to detect the $1.04 \mathrm{keV} \mathrm{K}_{\alpha}$ line of $\mathrm{Na}$. This demonstrates the capabilities at the low end of the periodic table. 


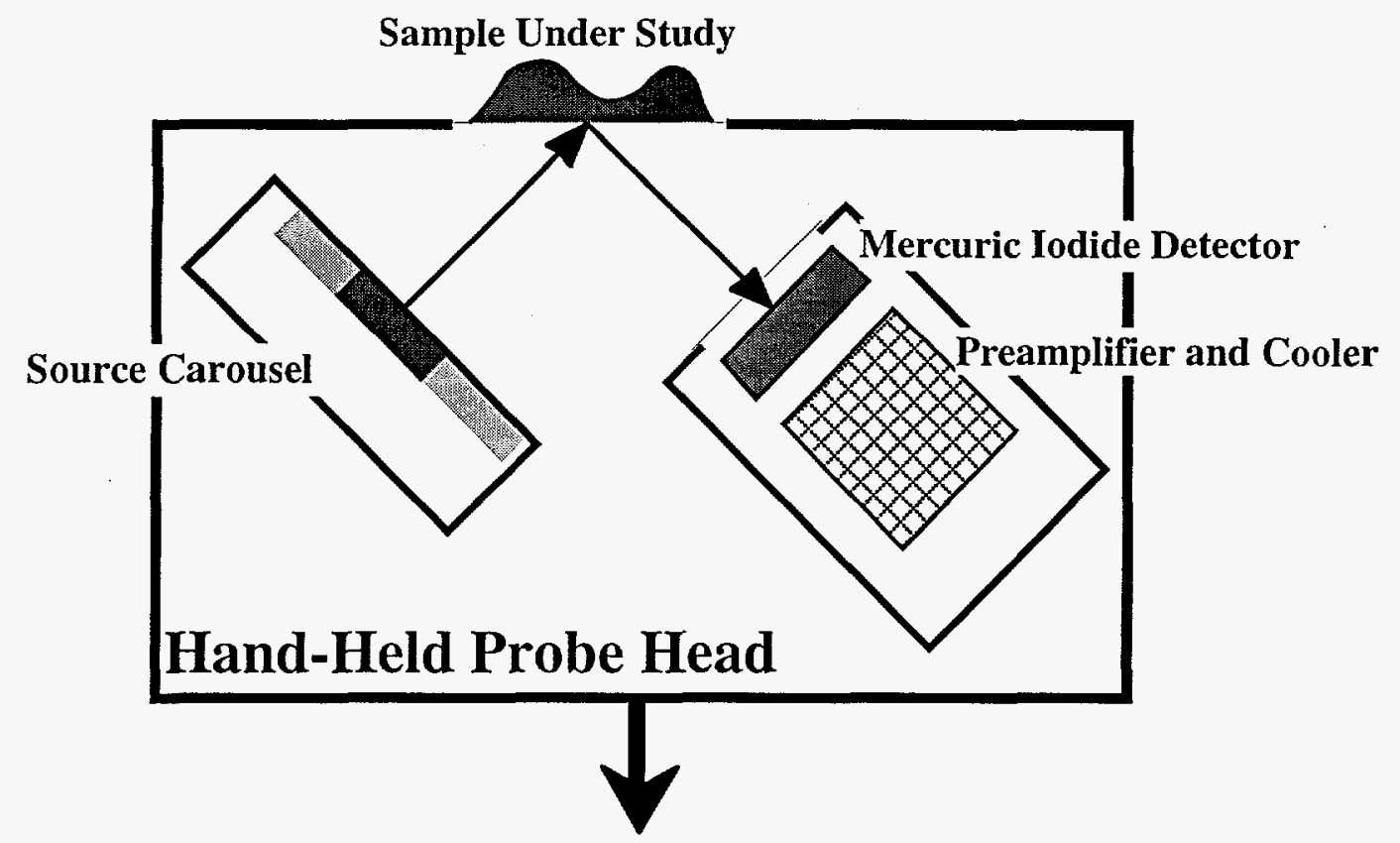

\section{To Signal Processing and Computer Unit}

Figure 8. Schematic of the design of a mercuric iodide portable XRF analyzer.

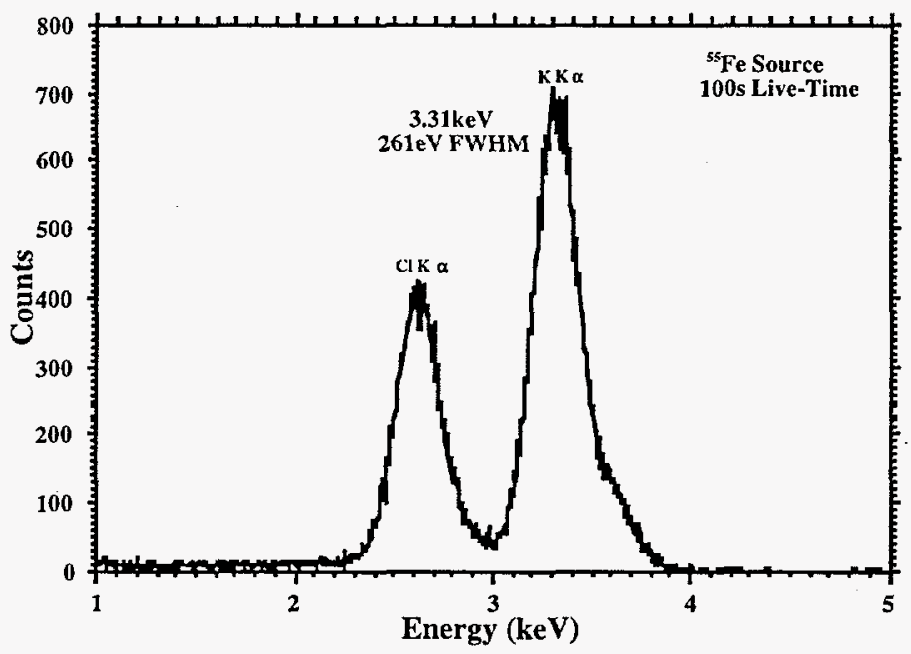

Figure 9. Spectrum of a $\mathrm{KCl}$ salt sample, taken with a $5 \times 5 \times 0.5 \mathrm{~mm}^{3} \mathrm{HgI}_{2}$ detector.

Figure 10 demonstrates the midrange capabilities of the instrument with the spectrum of a gallium arsenide ( $\mathrm{GaAs}$ ) sample excited with the ${ }^{109} \mathrm{Cd}$ source. The $K_{\alpha}$ and $K_{\beta}$ lines from the $G a$ and the $A s$ are visible and mostly separable. 


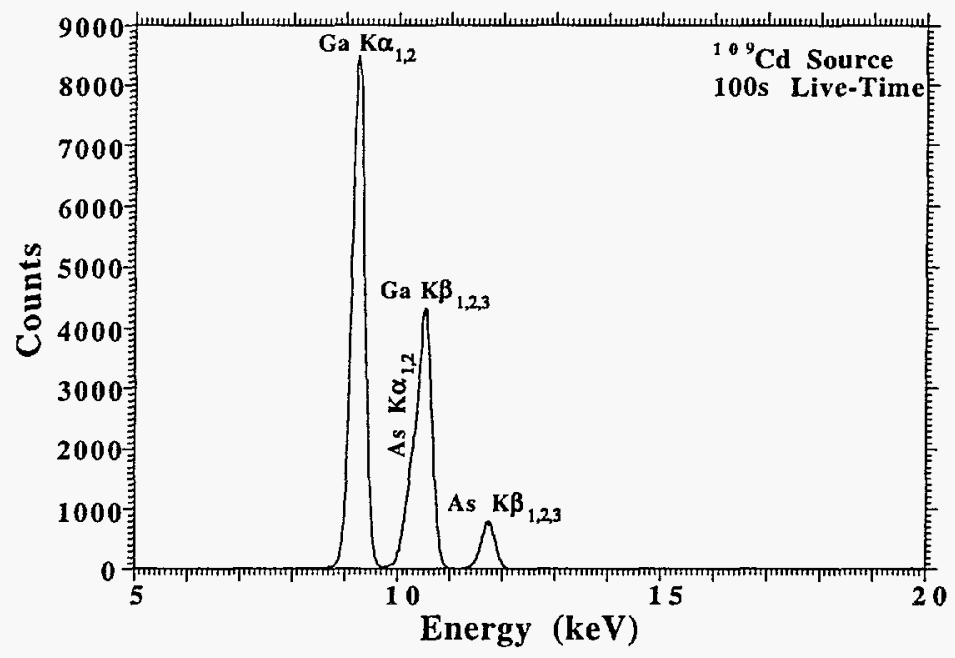

Figure 10. Example $X$-ray fluorescence (XRF) spectrum taken with the field portable instrument based on a $\mathrm{HgI}_{2}$ high-resolution spectrometer. This spectrum shows the toxic elements $\mathrm{Ga}$ and $\mathrm{As}$ as found in GaAs.

Figure 11 shows the spectrum from a more complicated sample, a piece of old lead-based paint. Here the emissions from the various elements are again well separated.

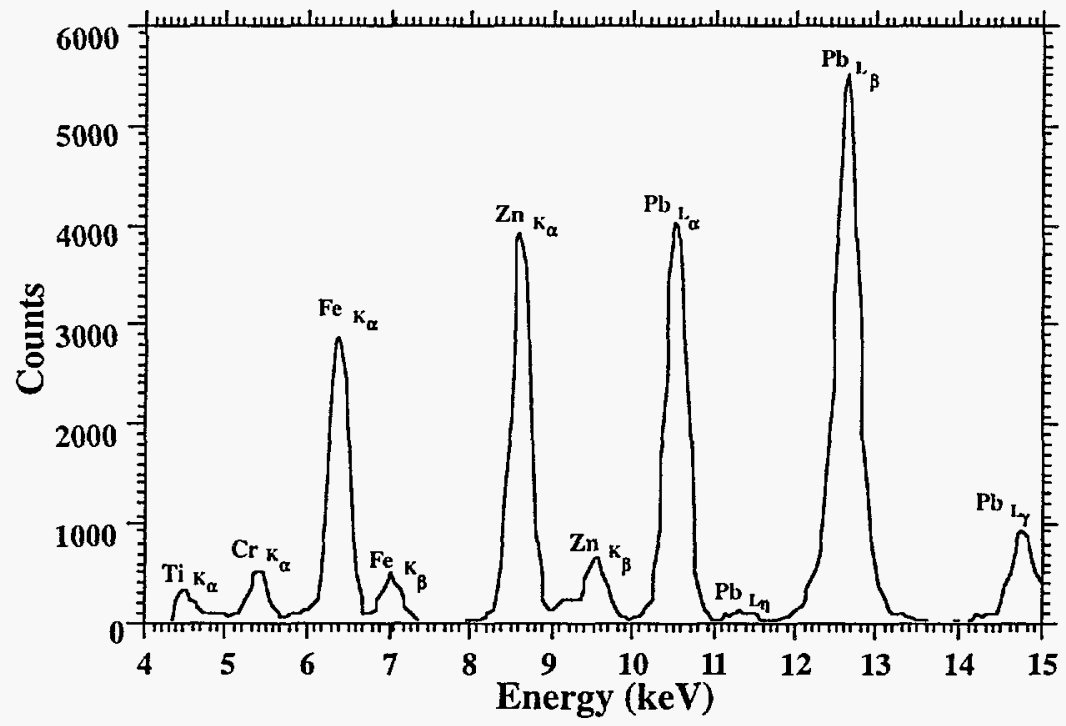

Figure 11. X-ray fluorescence spectrum from an old paint sample illuminated with ${ }^{109} \mathrm{Cd}$ X-rays.

Finally, Figure 12 shows the spectrum of higher atomic number elements from a complicated geological samples. The mercuric iodide detector provides the previously unavailable field capability of separating out for identification and quantification the uranium (U) content. 


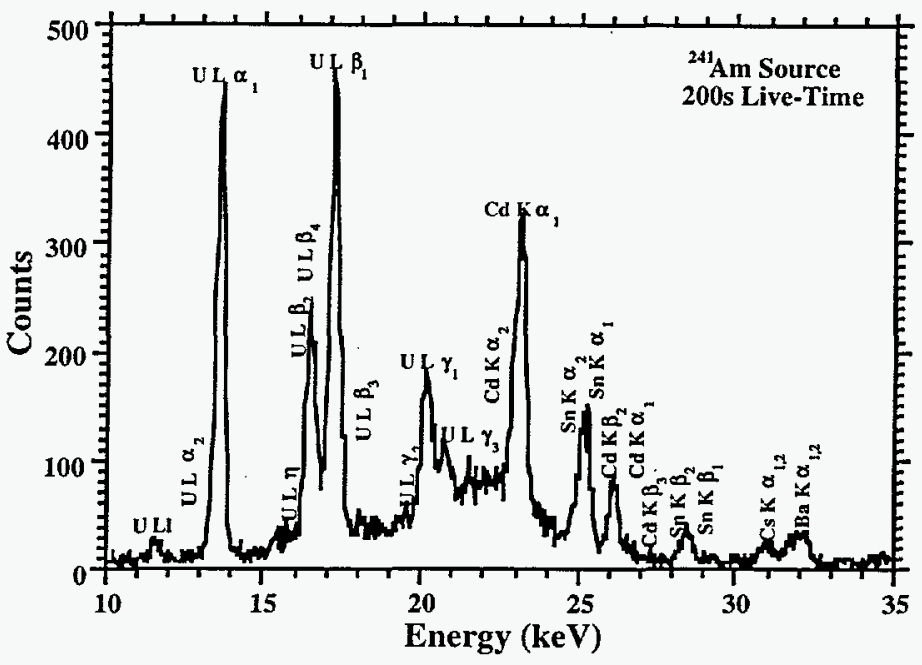

Figure 12. Spectrum of a geological sample containing several elements, including $\mathrm{U}, \mathrm{Cd}, \mathrm{Sn}, \mathrm{Cs}$, and $\mathrm{Ba}$, taken with a $5 \times 5 \times 0.5 \mathrm{~mm}^{3} \mathrm{HgI}_{2}$ detector. 


\section{Development of a Mercuric lodide Imaging Camera}

Devices for imaging the spatial distribution of gamma-ray emitting isotopes have been in wide use for many years, particularly in nuclear medicine. Gamma cameras are also critical in the imaging of radioactive waste stored in a variety of different containers. The conventional gamma imaging instrument employed today consists of an Anger camera9; a device consisting of an array of photomultiplier tubes (PMTs) attached to a large (approximately 1.0 meter in diameter) crystal of inorganic scintillating material such as $\mathrm{NaI}(\mathrm{Tl})$ or $\mathrm{BGO}$. When a gamma-ray photon interacts with the scintillating crystal in a gamma-camera, it produces an energetic electron via a photo-electric or Compton scattering process. The energetic electron produced by gamma $r a y$ interaction subsequently deposits its energy within a millimeter or so of the gamma-ray interaction site. When the electron loses its energy, it produces scintillating photons which are detectable by the PMTs. By determining the position centroid (Anger logic) of the light detected from several PMTs, the position of interaction of the photon can be determined. The scintillators used in conventional gamma cameras require some tens of $\mathrm{eV}$ of energy deposited to produce a single scintillating photon. Thus only a few tens of optical photons are produced per $\mathrm{keV}$ of energy deposited by the gamma ray. This low number of photons -- or more accurately the statistical fluctuation in this number of photons -- ultimately determines both the energy and position resolution of the detector used in existing gamma camera systems. The resolution with which a gamma-camera can encode position on the detector is not the same as the spatial resolution with which the gamma camera system can estimate the position of the gamma ray emitter. The position resolution of the collimator is also an important factor; in general, the position resolution in the resultant image is the convolution of the spatial response function of the collimator and the spatial response function of the detector. In modern large gamma cameras, the position resolution of the system is usually determined by the collimator. However, in a portable system employing a high resolution collimator (such as a pinhole collimator), the system resolution would be determined by the position resolution of the detector plane. Under these circumstances (i.e., portable gamma-cameras), the position resolution of the gamma ray imager may be limited by the scintillator/PMT detector. Furthermore, if one seeks to determine the isotope that is producing gamma ray emission, the ability to resolve isotopes is limited by the energy resolution of a scintillator based detector system.

An obvious method for overcoming the limitations of scintillator based systems is to use a semiconductor detector based gamma-camera. In a semiconductor detector, only a few $\mathrm{eV}$ are required to produced an electronhole pair, yielding a large reduction in the statistical fluctuations compared to the scintillator-based systems. Indeed, semiconductor gamma-ray spectrometers using cryogenic germanium long ago displaced scintillation systems as the best detection technique for energy spectroscopy. However, because of the cooling involved, it is often not practical to use a germanium detector, particularly for field use. Instead, one solution to producing improved miniature gamma-cameras is to use a room temperature semiconductor material (such as $\mathrm{HgI}_{2}$ ) to build the detectors.

There are several approaches that might be tried to produce a semiconductor detector with imaging capabilities. The most obvious solution is to configure a square array of individual detector elements into the desired image plane. However, since a typical imager could require a square array of dimensions $32 \times 32$ elements (1024 total elements), it is not economical to fabricate and assemble into an array such a large number of individual elements. 
The next most obvious approach is to fabricate a monolithic array of individual detector elements on a single semiconductor substrate. If lithograhic approaches to fabrication are used, it becomes practical to fabricate monolithic arrays with a suitable number of elements; however, reading out the signal from such an array would require very complex electronics. In general, to readout an $\mathrm{N} x \mathrm{~N}$ array of individual pixels requires $\mathrm{N}^{2}$ separate channels of readout electronics; for arrays larger than about $4 \times 4$ this becomes a very complex solution, particularly since each channel of electronics must be very high performance (low noise) to take advantage of the benefits of semiconductor detectors.

An alternative approach to reading out a semiconductor detector array was first proposed by Gerber et al. ${ }^{10}$ and is known as an orthogonal strip design. Such an approach is illustrated in Figure 13 and consists of rows of parallel electrical contacts (strips) placed at right angles to each other on opposite sides of the detector. By making use of the temporal coincidence between events recorded on both sides of the detector, it is possible to readout a $n$ effective array of $\mathrm{N}^{2}$ effective detector elements using only $2 \mathrm{~N}$ channels of readout electronics. The orthogonal strip approach was used for all of the imagers described in this report.

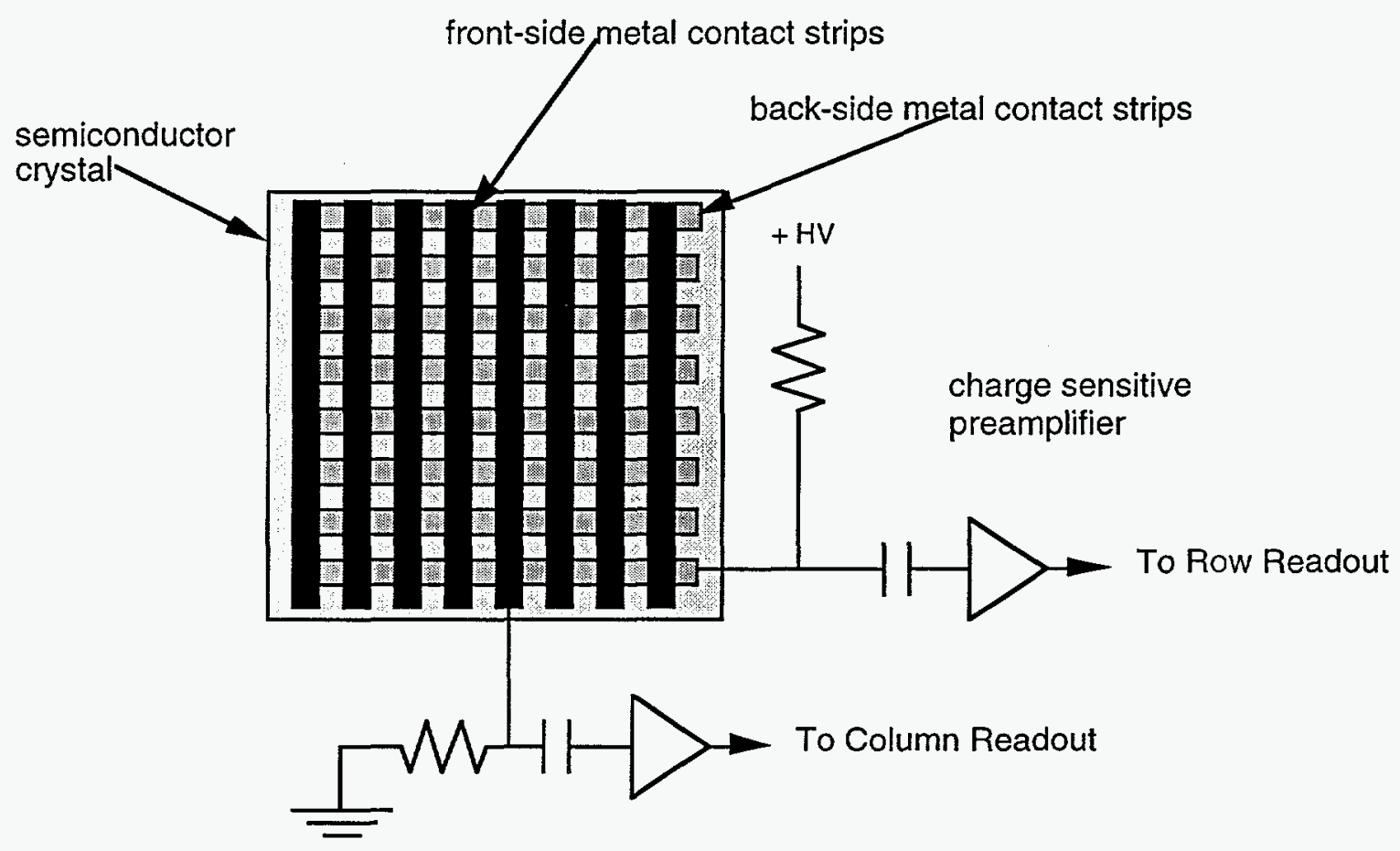

Figure 13. Diagrammatic view of an " $8 \times 8$ " orthogonal strip detector and front-end readout electronics. The metal contact strips a re deposited on opposite sides of a square piece of semiconductor wafer. Event localization on the detector plane is determined by scoring a coincidence event between a column and a row. Using this method reduces the complexity of the readout electronics considerably. In general, to readout an array of $\mathrm{N}^{2}$ effective pixels only requires $2 \times \mathrm{N}$ channels of readout electronics, as opposed to $\mathrm{N}^{2}$ channels of readout required for a detector consisting of an array of individual pixels.

Detectors were designed and built using $\mathrm{HgI}_{2}$ crystals as substrates. Our first detectors were $8 \times 8$ devices with an approximate thickness of $2.0 \mathrm{~mm}$ (see 
Figure 14). These $8 \times 8$ orthogonal strip detectors resulted in devices with 64 effective pixels with each pixel a square of approximately $0.125 \times 0.125 \mathrm{~cm}^{2}$ dimensions. These devices were placed on chip carriers (see Figure 15) that allowed them to be plugged directly into the readout electronics.

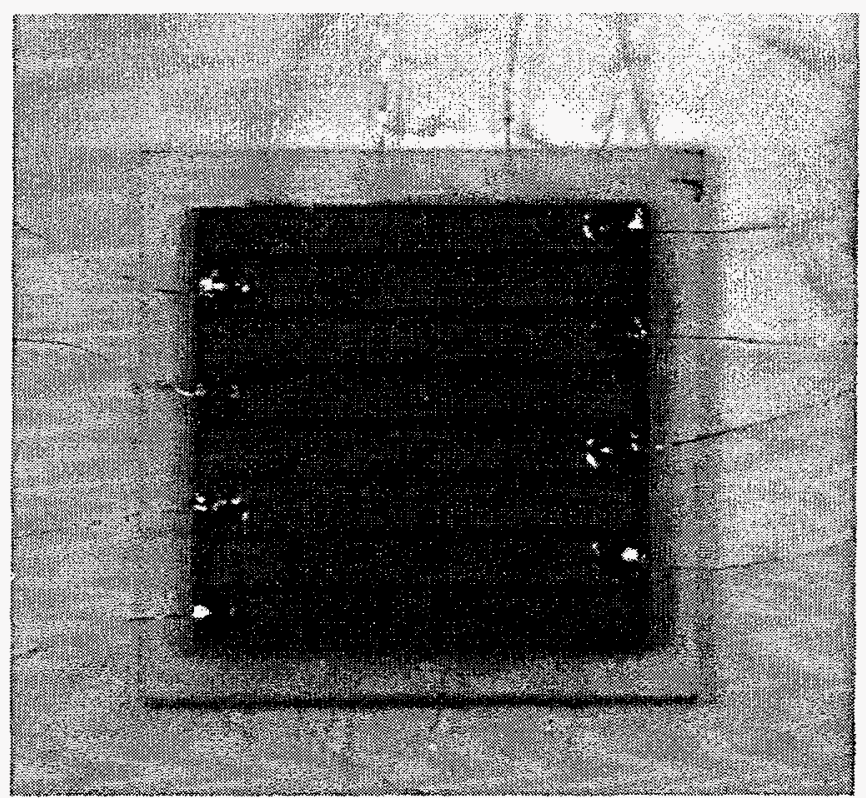

Figure 14. Photograph of an $8 \times 8 \mathrm{HgI}_{2}$ orthogonal strip detector, shown at five times actual size.

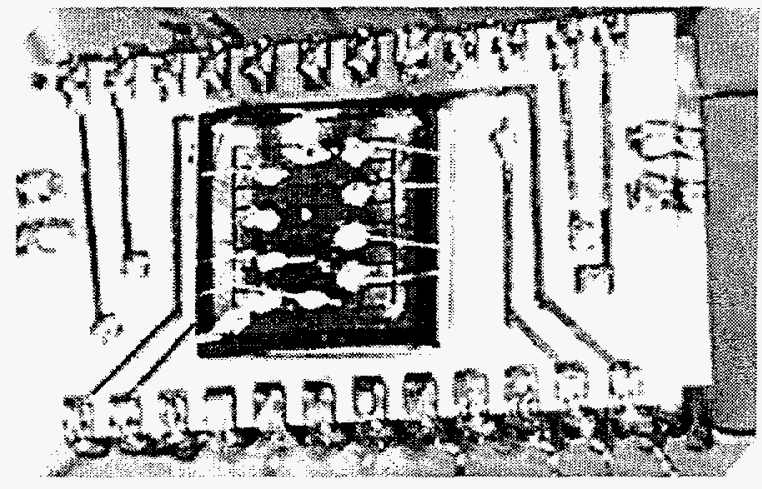

Figure 15. Photograph of an orthogonal strip detector mounted on a ceramic 24 pin DIP package.

Detectors were fabricated by evaporating metal contacts on to the surface of etched crystal substrates using a shadow mask to define the strip pattern. The detectors were mounted on standard 24 pin alumina dual in-line packages (DIPs) commonly used for hybrid electronic circuits. Fine gold wires $(25 \mathrm{~mm}$ diameter) were bonded to the metal contact strips using silver epoxy, the other end of the wire was then bonded to a metal foil pattern on the alumina substrate of the dual inline package. The packaged detectors could then $b \mathrm{e}$ inserted directly into a socket on the front-end readout circuit board. Subsequent testing of the detectors indicated that all of the detectors operated correctly as spectroscopic imaging devices, however, there was one strip that did not function. As of this writing it is not clear if the cause of the strip 
failure was in the detector or in the bonding and interconnection used to connect the detector to the readout electronics.

The system used to readout the $8 \times 8$ detector arrays made use of hybrid preamplifiers followed by NIM and CAMAC readout amplifiers and ADCs. A block diagram of the electronics used to readout the $8 \times 8$ detector array is shown in Figure 16. The performance of the readout system is determined largely by the hybrid preamplifiers which first amplify the signals from the $8 \times 8$ detector array. We chose to use a commercially available preamplifier array in our first prototype gamma camera. The preamplifiers (Lecroy HQV $820)$ are constructed in thick film hybrid technology and contain $8 \mathrm{channels}$ of preamplifier in a single wide 24 pin dual inline package (DIP). The rated performance of the preamplifiers translates to about $5 \mathrm{keV}$ FWHM of noise referenced to a gamma spectrum. We chose the HQV 820 preamplifiers because they were the only multi-channel units available commercially.

A circuit board was designed and built that accommodated two of the eight channel hybrid preamplifiers as well as the miscellaneous passive components to couple the detector to the preamplifier unit. The "front-end" circuit board containing the preamplifiers also contained a socket for holding an $8 \times 8$ detector. Although the additional capacitance and conductor trace length needed to socket the detectors would degrade the noise performance of the system somewhat, we decided that the tradeoff of being able test several detectors designs with the same readout circuit outweighed the slight performance degradation that socketing the detector induced. The front end circuit board was constructed of a Teflon derivative to minimize " $1 / \mathrm{f}$ " noise that would be induced by a conventional electronic circuit board. A photograph of the assembled circuit board is shown in Figure 17.

The front-end electronics were housed in a separate chassis which comprised the "camera head" and was connected via coaxial cables to the remaining readout electronics. The remaining electronics were housed in NIM bins and a CAMAC crate and interfaced to the readout computer with a SCSI CAMAC controller. A form of sparse readout -- implemented in hardware -was used to limit the amount of data the computer must obtain from the comparators and ADCs in the CAMAC crate. Signals from all 16 channels ( 8 columns and 8 rows, 64 pixels) were fed to a 16 channel comparator; when at least two comparators had fired, a master gate signal was triggered initiating the readout sequence. Additional event selection was also performed in software.

In order to readout the coincident signal from the strip detector, decode the pixel position, and visualize the gamma-ray intensity distribution at the detector plane, it was necessary to write software to control the gamma camera. The software interrogated the ADCs and discriminators in the CAMAC crate, decoded the position of interaction on the orthogonal strip detector, and created pulse height spectra of the interactions that occurred at each pixel. Another function of the software was to provide real-time feedback on the operation of the camera, and diagnostics of various camera functions (such as cross-talk between channels). The software was written in the high level control language "Kmax" to minimize development and reduce the amount of time spent writing low level CAMAC control routines. Figure 18 illustrates the graphical user interface (GUI) presented to the user when operating the software. The software, which executes on a Power Macintosh computer, also contains many more windows and dialog boxes than are shown in Figure 18, and can be called up for various diagnostic functions.

To demonstrate the capabilities of imaging with room temperature semiconductor detectors, the gamma camera system described above was tested with isotopic sources. Three general types of experiments were performed with the $\mathrm{HgI}_{2}$ detector array mounted in the gamma camera: flood field images of the detector plane to determine the uniformity of its response, imaging of 
objects with the aid of a pinhole collimator, and gamma-ray pulse height spectroscopy of isotopic sources.

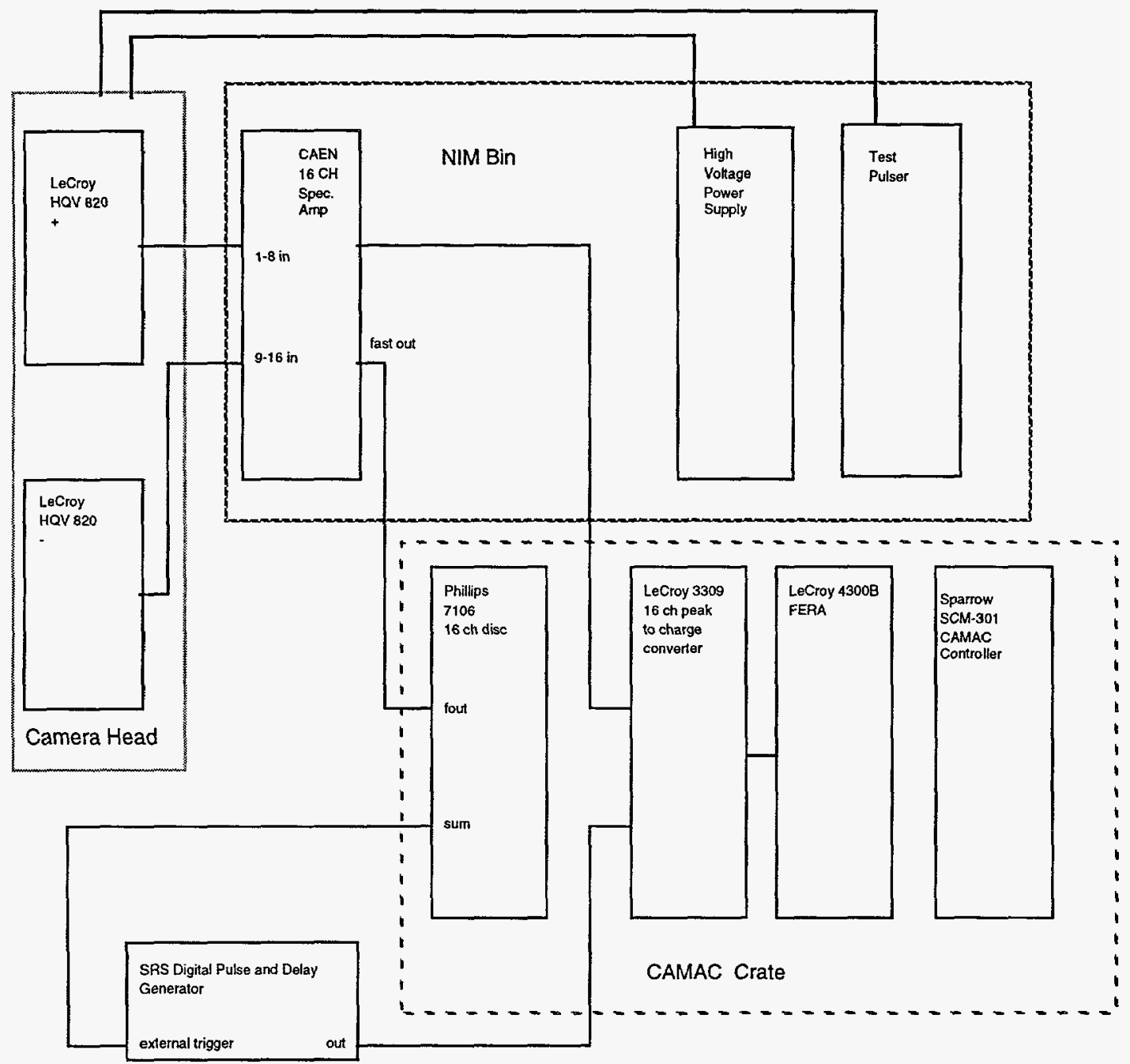

Figure 16. Block diagram of the electronic readout system used in the $8 \times 8$ gamma camera. The system may be viewed as consisting of two branches: one for counting hits (discriminator) and the other branch for spectroscopy (ADC). Pulses from the Lecroy HQV 820 preamps in the camera head are shaped and amplified by a CAEN 16 channel spectroscopy amplifier, these pulses are then fed to both a 16 channel discriminator and to a 16 channel ADC. Triggering of a read cycle is initiated in hardware whenever at least two channels are above the discriminator threshold, subsequent event selection is then performed in software after the CAMAC discriminators and ADCs have been read. 


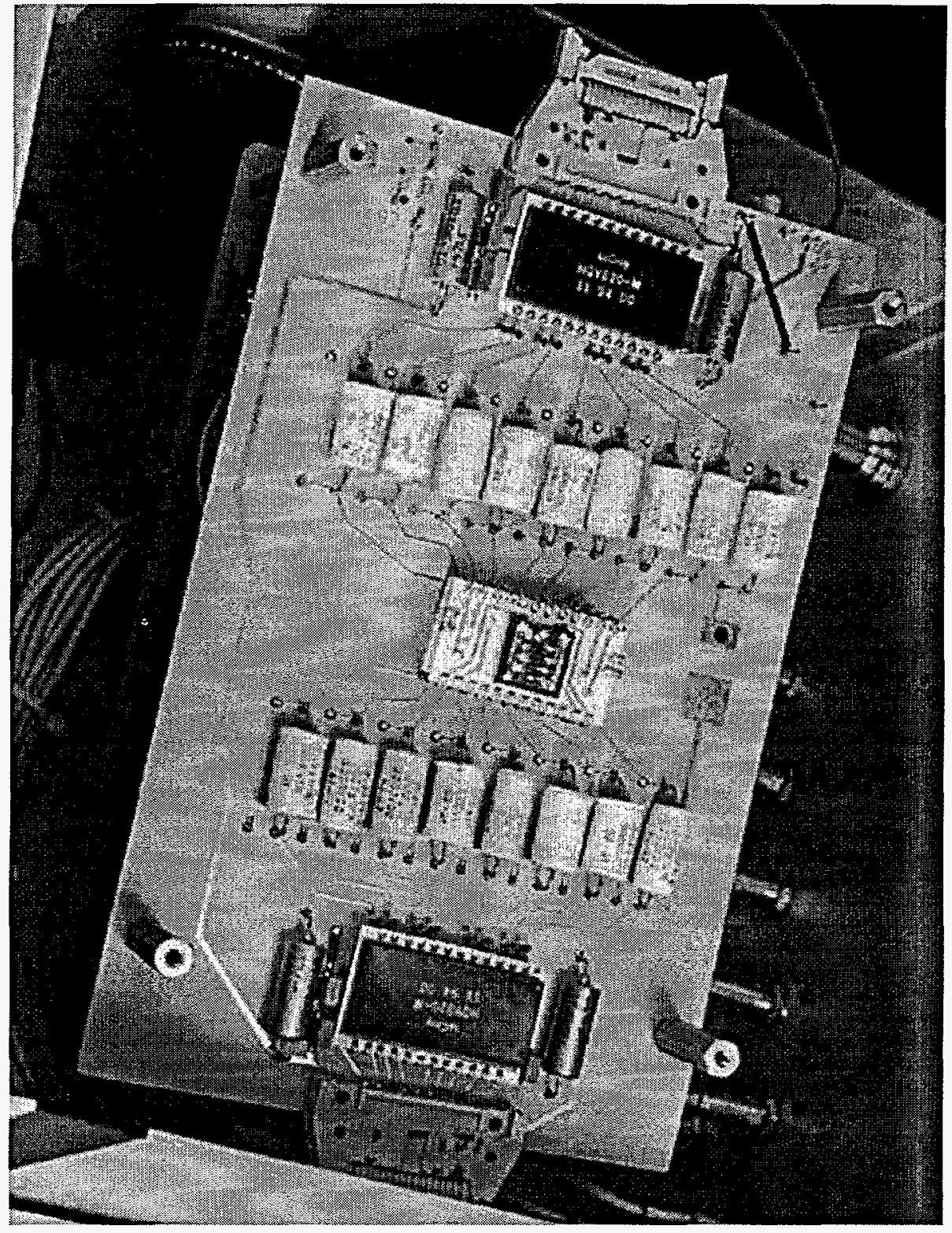

Figure 17. Photograph of the "front-end" circuit board used in the $8 \times 8$ gamma camera. An $8 \times 8$ detector module mounted in a DIP socket is visible in the center of the photograph. The white cylindrical objects on either side of the detector module are the decoupling capacitors (an AC coupled configuration was used to connect the detector strips to the preamp). The black rectangular objects on either end of the circuit board are the eight channel preamplifier arrays. The circuit board was constructed from Duroid -- a Teflon derivative -- to minimize the " $l / f$ " noise produced by the circuit traces between the detector and the preamplifier inputs. 


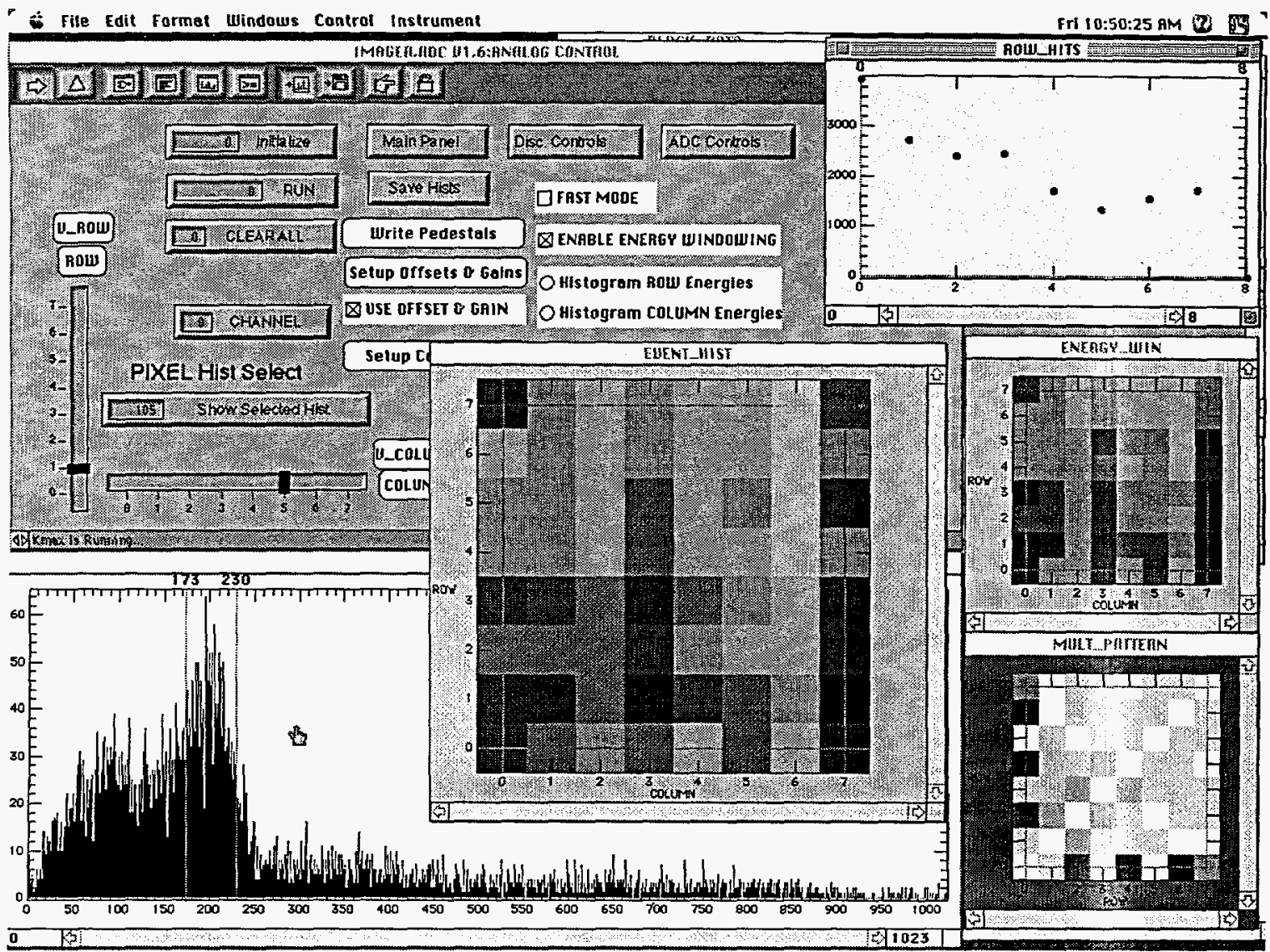

Figure 18. Printout of Graphical User Interface (GUI) of software for controlling the operation of the " $8 \times 8$ " gamma camera. A large number of windows and dialog boxes are available to the operator for controlling and monitoring the operation of the camera. The windows titled "EVENT_HIST" is a display of the total number of counts at each pixel. The window titled "ENERGY_WIN" is the display of intensity of hits that fall within a range of pulse height values selected on a master histogram of pulse height intensities.

Flood field images were obtained by mounting a ${ }^{133} \mathrm{Ba}$ source a few $\mathrm{cm}$ in front of the detector plane and recording the count rate at each pixel location as well as the energy spectrum of the source. Imaging studies were performed by mounting a pinhole collimator on the front of the gamma camera assembly and irradiating the collimator with isotopic sources of small active diameter. It was then possible to measure the position resolution on the detector $\mathbf{b} y$ recording images of the source as it was moved in a plane parallel to the detector plane.

Pulse height spectra were also acquired in both flood field mode and with the pinhole collimator. Two components were identified in the broadening of the pulse height spectra: Gaussian broadening due to random electronic noise ${ }^{11}$ and an asymmetrical distortion of the gamma-ray peaks due to charge trapping effects ${ }^{12,13}$. 


\section{Conclusions}

In this project, new instruments were developed for use in hazardous and radioactive materials management. These tools provide a previously unavailable capability for the detailed characterization of hazardous, radioactive, and mixed materials in the field, in situ. With these tools, it will be possible to more effectively and efficiently perform environmental remediation efforts in a variety of scenarios.

The fundamental enabling technology for these new instruments is the novel mercuric iodide high-resolution nuclear radiation spectrometer that is capable of operation at ambient temperatures and with minimal support and maintenance requirements. While mercuric iodide has been considered for many years as the semiconductor of choice for such applications, it is only through the improvement of the materials properties achieved in this project that the needed performance and yield of high quality detectors have been reached. In particular, the reduction of charge-trapping defects to a level sufficient to allow for the effective collection of all of the charge created by a photon interaction event has been achieved by coupling materials measurements with device performance evaluations in order to determine the particular materials properties most degrading performance, and eliminating their source. With these improvements, mercuric iodide devices with $\mathrm{high}$ energy resolution over the range of $x$-ray and gamma-ray photon energies of interest $(1 \mathrm{keV}$ to $1000 \mathrm{keV})$ can be reliably produced.

The first instrument developed was a field portable XRF instrument, for detailed, quantitative elemental analyses of any form of sample. The instrument developed can quantify elements ranging from $\mathrm{Na}$ to $U$ to the partper-thousand by using each of its three radioisotope excitation sources. The unit consists of a shoulder-strap-borne computer processing unit and a handheld probe head unit that can be readily carried by a field worker for a $n$ eight-hour shift with minimal notice -- the unit can be used in an anytime, anywhere mode. The unit was demonstrated to have sufficient energy resolution to easily separate and identify the individual elements in complicated samples.

Finally, an instrument which imaged and performed spectroscopy on gamma-rays was designed, built, and tested. The imaging system used a roomtemperature semiconductor detector made from $\mathrm{HgI}_{2}$. All detectors fabricated for this study were approximately $1.0 \mathrm{~cm}^{2}$ in active area and were of an $8 \times 8$ orthogonal strip design (64 effective pixels). Simple tests of the position resolution of the detector elements indicated that the $\mathrm{HgI}_{2}$ strip orthogonal strip detectors were capable of resolving the movement of a point source on the imaging plane with a resolution of better than $1.0 \mathrm{~mm}$. Further testing will be required to better quantify the spatial resolving capabilities of this instrument. The ability of the imaging detectors to resolve the energy of the detected gamma rays was also measured. It was found that energy resolution - as measured by pulse height spectroscopy -- was limited at low energies by electronic noise at approximately $15 \mathrm{keV}$ FWHM. At higher gamma-ray energies, the energy resolution was limited by hole trapping and extensive "hole-tailing" was observed on the low energy sides of the peaks. This behavior was expected, and is consistent with the performance of single element detectors made from these materials. Despite the deficiencies observed in the performance of our first system, we found our results (and those obtained by others using similar methods) to be quite encouraging. Orthogonal strip detectors made from room-temperature semiconductor detector materials appear to be a viable method for imaging the distribution of radionuclides with high spatial resolution and good energy resolution, particularly if the hole trapping effects in these detector materials can be 
minimized. We are currently working on improving the performance of our gamma-ray imaging devices by making use of electron-only device designs (analogous to the gridded ion chambers used with gas detectors ${ }^{1,14}$ ) to minimize hole tailing, and using a custom integrated circuit readout chip to reduce the electronic noise and increase the number of readout channels. 


\section{References}

1 Radiation Detection and Measurement, second edition, Glenn F. Knoll (John Wiley \& Sons, New York, 1989).

2 W. R. Willig, Nuclear Instruments and Methods 96, 615 (1971).

3 J. P. Ponpon, R. Stuck, P. Siffert, B. Meyer, and C. Schwab, IEEE Transactions on Nuclear Science NS-22, 182 (1975).

4 A. J. Dabrowski, W. M. Szymczyk, J. S. Iwanczyk, J. H. Kusmiss, W. Drummond, and L. Ames, Nuclear Instruments and Methods 213, 89 (1993).

5 H. L. Malm, T. W. Raudoff, M. Martina, and K. R. Zanio, IEEE Transactions on Nuclear Science NS-20, 500 (1973).

6 See, for example, R. C. Whited and M. Schieber, Nuclear Instruments and Methods 162, 119 (1979).

7 Electrodrift Purification of Materials for Room Temperature Radiation Detectors, Ralph B. James, John M. Van Scyoc III, and Tuviah E. Schlesinger, U. S. Patent Number 5,641,392, granted June 24, 1997.

8 Semiconductors for Room Temperature Nuclear Detector Applications, T. E. Schlesinger and R. B. James, Volume 43 of Semiconductors and Semimetals, R. K. Willardson, A. C. Beer, and E. R. Weber (Academic Press, San Diego, 1995).

9 H. O. Anger, "Gamma Ray Detection Efficiency and Image Resolution in Sodium Iodide", Nuclear Instruments and Methods 35, p. 693, (1964).

10 M. S. Gerber, D. W. Miller, P. A. Schlosser, J. W. Steidley, and A. H. Deutchman, "Position Sensitive Gamma Ray Detectors Using Resistive Charge Division Readout", IEEE Transactions on Nuclear Science NS-24, 182 (1977).

11 V. Radeka, "Low-Noise Techniques in Detectors", Annual Review of Nuclear Particle Science 38, 217 (1988).

12 R. O. Bell, "Calculation of Gamma-Ray Pulse Height Spectrum in a Semiconductor Detector in the Presence of Charge Carrier Trapping", Nuclear Instruments and Methods 93, A2 (1971).

13 W. Akutagawa and K. Zanio, "Gamma Response of Semi-Insulating Material in the Presence of Trapping and Detrapping", Journal of Applied Physics 40, 3838 (1969).

14 O. Frisch, British Atomic Energy Report, B R-49 (1944). 
APPENDIX A:

Publications Resulting from This Work

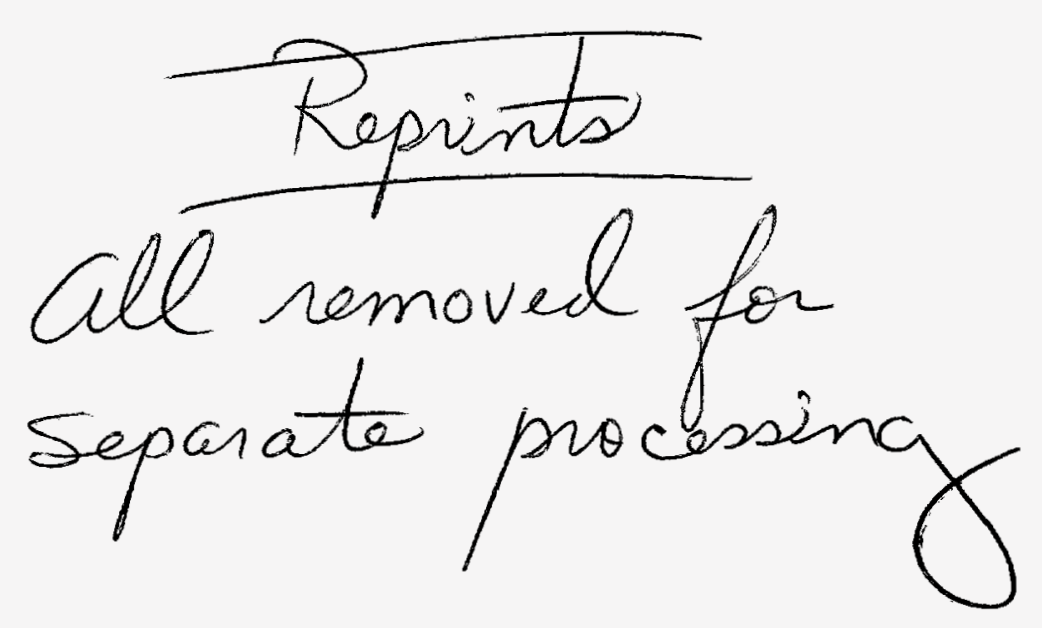

30 


\section{DISTRIBUTION}

1 D. Spears

U. S. Department of Energy

Office of Research and Development, NN-20

1000 Independence Avenue, SW

Washington, DC 20585

1 T. E. Schlesinger

Carnegie Mellon University

Department of Electrical and Computing Engineering

5000 Forbes Avenue

Pittsburgh, PA 15213-3890

1 J. Toney

Carnegie Mellon University

Department of Electrical and Computer Engineering

5000 Forbes Avenue

Pittsburgh, PA 15213-3890

1 A. Burger

Fisk University

Department of Physics

1000 17th Avenue, North

Nashville, TN 37208

$1 \quad$ M Roth

Hebrew University of Jerusalem

Graduate School of Jerusalem

91904 Jerusalem, ISRAEL

1 T. S. Gilbert

University of California

Department of Materials Science and Engineering

6532 Boelter Hall

Los Angeles, CA 90095-1595

1 M. S. Goorsky

University of California

Department of Materials Science and Engineering

405 Hilgard Avenue

Los Angeles, CA 90095-1595

1 H. Yoon

University of California

Department of Materials Science and Engineering

Box 951595

Los Angeles, CA 90095-1595

1 Y. C. Chang

University of Illinois

Department of Physics

1110 W. Green Street

Urbana, IL 61801 


\section{Distribution: (continued)}

1 G. F. Knoll

University of Michigan

Dean, College of Engineering

2309 EECS Building

Ann Arbor, MI 48109-2116

1 H. W. Yao

University of Nebraska

Department of Electrical Engineering

$209 \mathrm{~N}$ Walter Scott Engineering Center

Lincoln, NB 68588-0511

1 J. E. McKisson

Radiation Technologies, Inc.

P. O. Box 459

Alachua, FL 32616

1 X. J. Bao

T. N. Technologies, Inc.

P. O. Box 800

Round Rock, TX 78680-0800

1 G. S. Bench, LLNL, L-397

$2 \quad$ MSO320

MS1145

C. Meyers

D. McArthur

1 MS9001

T. O. Hunter, 8000;

Attn: J. B. Wright, 2200

J. F. Ney (A), 5200

M. E. John, 8100

W. J. McLean, 8300

R. C. Wayne, 8400

P. N. Smith, 8500

T. M. Dyer, 8700

P. E. Brewer, 8800
MS9007
A. E. Pontau
MS9056
J. Vitko
MS9161
MS9161
D. Cowgill
M. Schieber
MS9161
R. J. Henderson
MS9162
J. M. Van Scyoc
MS9402
MS9402
A. Antolak
D. Boehme
MS9402
D. H. Morse
MS9402
D. L. Medlin
MS9403
J. Wang
MS9404
G. Buffelben
MS9405
MS9405
MS9405
J. C. Lund
J. Hruby
MS9405
L. Franks
MS9409
R. B. James
R. H. Stulen 


\section{Distribution: (continued)}

1 MS9420

L. A. West, 8200

Attn: L. N. Tallerico, 8204

C. W. Sumpter, 8206

B. E. Affeldt, 8210

M. H. Rogers, 8220

$1 \quad$ MS9671

MS9671

$\begin{array}{ll}1 & \text { MS9671 } \\ 1 & \text { MS9671 }\end{array}$

1 MS9671

A. J. West, 8240

$3 \quad$ MS9018

MS0899

MS9021

MS9021

MS0320

MS0320

MS0320

B. A. Brunett

E. Cross

H. Hermon

N. R. Hilton

R. W. Olsen

Central Technical Files, 8940-2

Technical Library, 4916

Technical Communications Dept. 8815/Technical Library, 4916

Technical Communications Dept. 8815, for DOE/OSTI

C. Meyers, LDRD Office

L. M. Lopez, LDRD Office

D. L. Chavez, LDRD Office

C. L. Harvey, LDRD Office 